\title{
IMPROVING THE VOLUMETRIC STABILITY OF WHITE CEMENT BY USING SOME ADDITIVES
}

\author{
*Marwa A. Anber ${ }^{1}$
}

Mohammed A. Abdulrehman'

1) Materials Engineering Department, College of Engineering, Mustansiriyah University, Baghdad, Iraq

\begin{abstract}
Abstract: This study looked at the effects of three types of additives: limestone powder, Arabian gum AG, and polyvinyl alcohol (PVA), on White Cement Mortar's Physical and Mechanical Properties the mixing ratio for dry shrinkage was 1:2. (Cement: sand) while for other tests, it was 1:2.75 (cement: sand). The limestone powder proportions are $(5 \%, 10 \%$, and $15 \%)$ by weight of white cement, while the AG ratios are $(0.2,0.5$, and 0.8$) \%$ by weight of white cement, the polyvinyl alcohol ratios are $(2 \%, 4 \%$, and $6 \%$ ). This study was focused at the compressive and flexural strength of the modified mortar, as well as water absorption and drying shrinkage. According to the findings, utilizing of limestone powder as additive in white cement mortar is not advised. Since it had the negative affect on dry shrinkage of the mortar. Furthermore, polymer additives such as AG and PVA significantly increase the reduction of ability of forming crack in white cement mortar. Furthermore, the optimal additive percentages of AG and PVA are 0.5 percent and $6 \%$, respectively.
\end{abstract}

Keywords: dry shrinkage, cracks, white cement, volumetric stability

\section{Introduction}

In the construction sector, white cement is widely used for aesthetic purposes, but it also has a variety of functional applications. White cement can be used for surface treatments on its own, with or without a color. White cement is also utilized in decorative works such as architectural fittings, statues, and terrazzo. Designers and architectural engineers are encouraged to utilize white cement in the mix of ornamental concrete in a variety of sizes and forms since it is known for its flexibility before final setting. Virtually, for a variety of reasons, white cement concrete is utilized to improve energy efficiency. For starters, it is extremely heat reflecting, reducing the requirement for air conditioning in structures. Second, it can improve lighting in open-plan buildings, as a result when white cement concrete is used, the long-term cost of the cooling/heating and lighting systems is lowered. In terms of construction White cement concrete is similar to Portland cement concrete in that it can be utilized in the same way. On the internal concrete face, if the concrete cover spalls or surface cracks, less care of the concrete surface is required [1].

Except for the color, white cement has essentially the same qualities as grey cement. Cement's whiteness is determined by the raw materials used and the production process used. The whiteness and undertone of cement are influenced by metal oxides, notably iron and manganese. Mortar is a mixture of cement, sand, and water that can be used for a variety of purposes. To provide the mortar diverse

*Corresponding Author: EBMA035@uomustansiriyah.edu.iq 
properties and characteristics, additives are frequently employed [2]. Ordinary Portland cement is cheaper than white Portland cement. White cement has a lower strength than typical Portland cement [3]. Because white cement has early age shrinkage cracking difficulties, it has few structural applications in building construction [4]. White cement is also utilized extensively in the production of precast components. The widely used for creating cast stones of attractive look is used to create beautiful precast members. It is employed in architectural beauty, interior and outdoor decorations, floorings, and ornamental concrete goods such as idols due to its whiteness, whereas grey cement is primarily used for building purposes [5]. There are many researchers who have presented studies on white cement and the additives was used in this study such as, Carbone et al., had investigated the impact of polymers on properties of white Portland cement pastes in the hardened state [6]. Wang et al investigated the chemical interaction between polymer and cement in polymer-cement concrete [7]. Cherop et al, had looked into the effects of non-ionic cellulose ethers on white Portland cement properties [8]. Torres-Carrasco et al. investigated the use of synthetic feldspars to improve thermal efficiency in cement mortars [9]. Chen et al, had discovered that replacing cement paste with limestone fines improved dimensional stability significantly. Using limestone fines to fill in spaces between aggregate particles can cut down on the amount of cement paste required to fill the holes [10]. Knapen et al, had used two types of binder are used in these modified cement mortar and concrete: a hydraulic cement system and a polymer system. The aggregates are incorporated in a polymer and cement hydrate network that is interpenetrating. Polymer modification is a common technique for overcoming some of the drawbacks of traditional mortars and concretes, such as low tensile and impact strength, limited corrosion resistance, poor behavior under extreme conditions, and poor adherence of new mortar or concrete to existing concrete [11]. Abbas et al, had proved that the addition of PVA reduces the water content of the cement mortar, implying that the addition of PVA reduces the porosity of the cement mortar [12]. Mohamed et al, had discussed the high viscosity property of $\mathrm{AG}$ in the construction industry and prove that AG can be utilized as a water-reducing admixture, resulting in lower chemical additive demand and improved flow ability of AG mortar mixes [13]. Courard et al, had discovered that when the limestone is ground to a finer fineness than the clinker, it will contribute to the space filling reactions, which reduce porosity and increase strength over a 28-day period at room temperature. When the limestone is ground to a finer fineness than the clinker, it will improve workability but have little effect on the hydration reactions. In this scenario, it should be classified simply as filler [14].

The aim of this study is to use three additives to reduce the possibility of cracks occur in white Portland cement within the White cement mortar, such as limestone powder and water-soluble polymers PVA and AG.

\section{Experimental}

\subsection{Materials}

\subsubsection{White Portland cement}

The white cement utilized in this investigation complies with Iraq Standard No.5 criteria (IQS5:1993). The white cement's chemical synthesis is shown in table 1 below.

Table 1. Chemical synthesis of the white cement.

\begin{tabular}{ccc}
\hline Constituents & \% weight & $\begin{array}{c}\text { Specification limits } \\
\text { of IQS (5:1993) [15] }\end{array}$ \\
\hline $\mathrm{CaO}$ & 68.12 & - \\
$\mathrm{A} 12 \mathrm{O} 3$ & 4.75 & - \\
$\mathrm{Fe} 2 \mathrm{O} 3$ & 0.50 & -
\end{tabular}




$\begin{array}{ccc}\mathrm{SiO} 2 & 24.03 & - \\ \mathrm{So} 3 & 2.57 & <3 \\ \mathrm{MgO} & 0.77 & <5 \\ \text { Loss on } & 3.37 & <4 \\ \text { ignition } & & <1.5 \\ \text { Insoluble } & 0.46 & \\ \text { residue } & & 0.66-1.022 \\ \text { Lime } & 0.9 & \\ \text { saturation } & & - \\ \text { factor } & & \\ \text { Total } & 100 & \end{array}$

\subsubsection{Fine aggregate}

Standard sand was used in this research depend on ASTM C778 [16]. Table 2 shows grading of fine aggregate.

Table 2. Grading of fine aggregate

\begin{tabular}{cc}
\hline Sieve size & Passing percent \% \\
\hline $1.18 \mathrm{~mm}$ & 100 \\
$0.600 \mathrm{~mm}$ & 98.6 \\
$0.425 \mathrm{~mm}$ & 74.1 \\
$0.300 \mathrm{~mm}$ & 24.3 \\
$0.150 \mathrm{~mm}$ & 0.12 \\
\hline
\end{tabular}

\subsubsection{Limestone powder}

The limestone powder is marble stones soft powder from the northern region was used in this investigation, which is also known commercially as Crushers. Table 3 shows the results of the chemical analysis of limestone powder.

Table 3. Chemical synthesis of limestone powder

\begin{tabular}{cc}
\hline Oxides & \% Content \\
\hline $\mathrm{Sio} 2$ & 2.51 \\
$\mathrm{CaO}$ & 52.68 \\
$\mathrm{Fe} 2 \mathrm{O}$ & 0.26 \\
$\mathrm{MgO}$ & 0.73 \\
$\mathrm{SO} 3$ & 3.12 \\
$\mathrm{Al} 2 \mathrm{O}$ & 0.85 \\
Loss on ignition & 39.7 \\
\hline
\end{tabular}

\subsubsection{Arabian gum $(A G)$}

AG used in this study was imported from Sudan and available in local markets, the properties of AG are shown in table 4.
Table 4. Properties of AG

\begin{tabular}{|c|c|}
\hline Properties & Results \\
\hline Stability & Stable, not compatible \\
\hline \multirow{3}{*}{ Water Solubility } & $\begin{array}{l}\text { with the alcohols and the } \\
\text { oxidizing agents. }\end{array}$ \\
\hline & Water-soluble. An \\
\hline & $\begin{array}{l}\text { aqueous solution is acidic } \\
\text { to the litmus. }\end{array}$ \\
\hline Density & $1.35 \mathrm{~g} / \mathrm{cm} 3$ \\
\hline Color & White to yellow-beige \\
\hline form & fine powder \\
\hline
\end{tabular}

\subsubsection{Polyvinyl alcohol (PVA)}

Polyvinyl alcohol was supplied from Celvol 603 (Celanses chemical). Table 5 shows the properties of PVA as reported by the manufacturer.

Table 5. Properties of PVA

\begin{tabular}{cc}
\hline Properties & Results \\
\hline Appearance & White \\
PH & $5-7$ \\
Viscosity & $23-27$ \\
Melting point & $185^{\circ} \mathrm{C}$ \\
\hline
\end{tabular}

\subsubsection{Water}

Distilled water was used in this study.

\subsection{Distinguish of Mixtures}

In this work, a total of four groups of mixtures was prepared. The first group had one mixture was prepared as control samples. The control mixtures were made of Fine Aggregate (Sand), cement and water only. With no addition, therefore the results of this group are considered zero for the improvement in cement.

The first group is a mixture (cement, limestone, sand, water) was prepared with different content of limestone. We partial replacement of cement by ratio are $(5 \%, 10 \%, 15 \%)$ by weight of white cement.

The second group is a mixture (cement, PVA, sand, water) was prepared with different content of (PVA). We partial replacement of cement by 
ratio are $(2 \%, 4 \%, 6 \%)$ by weight of white cement.

The third group is a mixture (cement, AG, sand, water) was prepared with different content of. We partial replacement of cement by ratio are $(0.2 \%, 0.5 \%, 0.8 \%)$ by weight of white cement.

Table 6 shows in details distinguish of all mortar mixtures that were used in this study.

Table 6. Mix proportion of white cement mortar

\begin{tabular}{cccc}
\hline Mixtures & $\begin{array}{c}\text { Limeston \% } \\
\text { wt. }\end{array}$ & $\begin{array}{c}\text { AG \% } \\
\text { wt. }\end{array}$ & $\begin{array}{c}\text { PVA \% } \\
\text { wt. }\end{array}$ \\
\hline WC & - & - & - \\
WL5 & 5 & - & - \\
WL10 & 10 & - & - \\
WL15 & 15 & - & - \\
WG2 & - & 0.2 & - \\
WG5 & - & 0.5 & - \\
WG8 & - & 0.8 & - \\
WP2 & - & - & 2 \\
WP4 & - & - & 4 \\
WP6 & - & - & 6 \\
\hline
\end{tabular}

\section{Methods}

1. The compressive strength test is determined according to ASTM: C150 [17] using the dimensions of $50 \times 50 \times 50 \mathrm{~mm} \mathrm{~A}$ digital compressive machine (Control) with a capacity of $250 \mathrm{kN}$ was used to test the compressive strength cubes. The tests were conducted at 28 days of age, with an average of three test results used for each test. This test is useful in determining the mechanical qualities of cement mortar (strength and durability). the compressive strength is determined by using the formula below:

$\sigma=P / A$

Where:

$\sigma=$ Compressive Strength, $\mathrm{P}=$ Load

$\mathrm{A}=$ Cross sectional area
2. Modulus of rupture was tested Using an ASTM C 192 [18] prism with dimensions of $40 \times 40 \times 160 \mathrm{~mm}$. Flexural strength is usually stated in design codes as the Modulus of Rapture (MOR). Flexural strength can be calculated using the ASTM C 293 three-point loading test, according to the standard. All prisms in this study are tested on a test machine with a capacity of 30 KN. This test demonstrates the significance of material bending and breakage. Modulus of rupture is determined by using the formula below:

$$
M O R=\frac{3 P L}{2 b d^{2}}
$$

$\mathrm{P}=$ maximum load in $\mathrm{N}, \mathrm{L}=$ specimen length between supports in $\mathrm{mm}$

$\mathrm{b}=$ fracture cross section width in millimeter $\mathrm{d}=$ the height of the fracture cross section in millimeters

The prisms are cast and cured under the same conditions as the compressive strength test specimens.

3. Absorption Test, After the specimens have been demolded They're weighted and drenched in water, then quickly removed and dried with a piece of cloth to remove any remaining water. The specimens are weighed again after this test, which reveals the holes in the material. The water absorption is determined by applying the Eq. 3:

Water absorption $\%=\frac{(W s-W d)}{W d} \times 100 \%$

Where;

Ws: weight of the soaked pieces in gm. wd: weight of the dry pieces in gm

4. Dry shrinkage test, was determined based on ASTM: C 596-04 [19]. a flow table test must be performed before inserting the materials to be tested in the molds to establish how much water each sample 
requires to achieve a flow value of 110 percent. Test specimen molds must have dimensions of $25 \times 25 \times 285 \mathrm{~mm}$. before and after drying, the length of mortar bars differed. is measured using this method. This test demonstrates the likelihood of cracks in the mortar. determined by applying the Eq. (4)

dry shrikage $\%=$

(Li after 25 day (mm) - L after 3 day (mm))/

(leff $(250 \mathrm{~mm})) \times 100$

Where: -

$\mathrm{L}_{\mathrm{i}}$ - Length of specimens after 25 days. (mm)

L- Length of specimens after 3 days. ( $\mathrm{mm}$ )

$\mathrm{L}_{\mathrm{eff}}$ - The effective length of the test specimen. (250mm)

\subsection{Preparation for Compressive Strength and Flexural Strength:}

The procedure of prepared mortar has been divided into four main branches. Initially, it was weighed and the amount of limestone, PVA, AG, sand, cement and water were calculated.

1. Weighing the components by a sensitive digital balance of $0.01 \mathrm{gm}$ digits.

2. Dry mixing of additives with cement mortar for case (Limestone, AG) while in case of (PVA) additive must be dissolve the polymer in water before adding to mixture.

3. Sand and cement mixed together for about two minutes, the water and additive was added to the mixture and mixed for four minutes according to ASTM C305 [20].

4. The mortar was withdrawn from the mixer and put into clean, oiled molds; the sample densification was done in two layers on a vibrating table, with each layer vibrating for 1 to 1.5 minutes until no air bubbles emerged on the casting surface.

5. A spatula was used to finish the samples' surfaces.
6. Molds were covered with plastic sheets after molding to preserve moisture, and samples were maintained at room temperature for 24 hours in the lab.

7. The samples were then demolded and cured in water before being tested.

\section{Results and Discussion}

\subsection{Compressive Strength (fc)}

Table 7 shows the results of compressive strength test for each samples.

Table 7. results of compressive strength test

\begin{tabular}{cc}
\hline Mixtures & fc (MPa) \\
\hline WC & 26.4 \\
WL5 & 26.2 \\
WL10 & 25.7 \\
WL15 & 25.5 \\
WG2 & 27.3 \\
WG5 & 29.6 \\
WG8 & 29.4 \\
WP2 & 26.3 \\
WP4 & 26.3 \\
WP6 & 26.0 \\
\hline
\end{tabular}

In general, the higher the percentage of addition of limestone powder, the value of compressive strength decreases, but when using Arabian gum (AG), the highest value of compressive strength is obtained when adding $\mathrm{AG}$ by $0.5 \%$ wt. of white cement, but when adding polyvinyl alcohol, the strength Compression is slightly decreased.

\subsection{Modulus of rupture (MOR)}

Table 8 shows the results of MOR test for each samples.

Table 8. results of MOR test

\begin{tabular}{cc}
\hline Mixtures & MOR $($ MPa $)$ \\
\hline WC & 6.4 \\
WL5 & 6.2 \\
WL10 & 5.9 \\
WL15 & 5.4 \\
WG2 & 6.5 \\
WG5 & 6.7 \\
WG8 & 6.7
\end{tabular}




\begin{tabular}{ll} 
WP2 & 6.4 \\
WP4 & 6.6 \\
WP6 & 6.4 \\
\hline
\end{tabular}

In general, the addition of limestone powder is inversely proportional to the value of the MOR, but when using (AG), the highest value of MOR is obtained when adding $0.5 \% \mathrm{AG}$ and $0.8 \%$ wt. of white cement, as well as when adding polyvinyl alcohol, it gives the highest value of MOR when added by $4 \%$ wt. of white cement.

\subsection{Absorption of Water}

Table 9 shows the results of absorption test for each samples.

Table 9. results of absorption test

\begin{tabular}{cc}
\hline Mixtures & Absorption \% \\
\hline WC & 3.88 \\
WL5 & 3.99 \\
WL10 & 4.06 \\
WL15 & 4.17 \\
WG2 & 3.71 \\
WG5 & 3.70 \\
WG8 & 3.78 \\
WP2 & 3.81 \\
WP4 & 3.77 \\
WP6 & 3.76 \\
\hline
\end{tabular}

When limestone powder is added, it causes an increase in the absorption rate. When using AG, the absorption rate decreases and reaches the lowest absorption rate when using AG by $0.5 \%$ wt. of white cement, as for when using PVA, the lowest absorption value is obtained when adding the PVA by $6 \%$ wt. of white cement.

\subsection{Dry Shrinkage}

Table 10 shows the results of dry shrinkage test and flow table test for each samples.

Table 10. results of absorption test

\begin{tabular}{ccc}
\hline Mixtures & $\begin{array}{c}\text { W/C determined by } \\
\text { flow table test \% }\end{array}$ & $\begin{array}{c}\text { Dry } \\
\text { shrinkage \% }\end{array}$ \\
\hline WC & 0.53 & 0.007 \\
WL5 & 0.51 & 0.012
\end{tabular}

\begin{tabular}{lll} 
WL10 & 0.48 & 0.026 \\
WL15 & 0.46 & 0.039 \\
WG2 & 0.50 & 0.006 \\
WG5 & 0.42 & 0.002 \\
WG8 & 0.33 & 0.001 \\
WP2 & 0.54 & 0.007 \\
WP4 & 0.55 & 0.005 \\
WP6 & 0.57 & 0.002 \\
\hline
\end{tabular}

It is evident from the above table that the limestone powder increases the possibility of cracks due to its negative effect on the shrinkage property, while the AG has a positive role in reducing the shrinkage and gives the best value when added by $0.5 \%$ wt. of the white cement as well as the PVA, it also plays a positive role by reduces shrinkage and gives the best results when it is used with $6 \%$ wt. of white cement.

\section{Conclusions}

The following conclusions can be made from the above-mentioned test results:

1. Limestone powder should not be utilized in white cement mortar due to its negative effect on the dry shrinkage property.

2. The use of Arabian gum and polyvinyl alcohol considerably reduce the possibility of cracks occur in white cement mortar. Furthermore, Arabian gum is more effective than PVA because it requires less doses to produce the same or greater benefits.

3. The best addition AG and PVA percentages are 0.5 and $6 \%$, respectively. In comparison to other percentages, these two percentages improve the mechanical and physical properties of white cement mortar.

4. The addition PVA leads to decrease the porosity of white cement mortar

\section{Acknowledgements}

The authors would like to express their gratitude to the staff of Mustansiriyah University 
(www.upomustansiriyah.edu.iq) Bagdad, Iraq, for their assistance with this project.

\section{Conflict of Interest}

The author confirms that the publication of this article causes no conflicts of interest.

\section{References}

1. Farny J. A.,(2001) "White Cement Concrete, EB217. Portland cement Association, Skokie, Illinois, USA."

2. civilengineeringbible, 2006, "THE WHITE GUIDE.".

3. https://civilengineeringbible.com/article.p hp?i=267,(May 26, 2021), "White Portland Cement use cases;Pros and ConsCivilEngineeringBible.".

4. Hamad B. S. ,January 1994, “Comparative studies of Type I and White Portland cements .,".

5. https://theconstructor.org/concrete/whitecement/23732/, (Jun. 19, 2021) ,"White Cement - Manufacture, Properties and Uses - Concrete Technology - The Constructor.”.

6. R. G. P. C. E. Carbone, H. Santos, R. C. de O. Romano, "2. C. E. Carbone, H. Santos, R. C. de O. Romano, and R. G. Pileggi,)2013( 'Effect of polymer additions on pastes of white cement on hardened state' Ambient. Construído, vol. 13, no. 3, pp. 317-330."

7. Ru Wang L. C., L J. i, Zhang T., "3. Ru Wang, J. Li, Zhang T., Czarnecki L., (2016) ' Chemical interaction between polymer and cement in polymer-cement concrete', Bulletin of the Polish Academy of Sciences Technical Sciences, Vol 64, no. 4, December."

8. Kosgey3 E. K. and P. T. C. S. L. K., 2017, "Effect of Non-Ionic Cellulose Ethers on Properties of White Portland Cement," vol. 12 , no. 10 , pp. 2502-2508,

9. Torres-Carrasco M., Enríquez E., TerrónMenoyo L., Cabrera M. J., Muñoz D., and. Fernández J. F, 2021,"Improvement of thermal efficiency in cement mortars by using synthetic feldspars," Constr. Build.
Mater., vol. 269, no. xxxx, p. 121279, doi: 10.1016/j.conbuildmat.2020.121279.

10. Chen J. J., Kwan A. K. H., and Jiang Y., 2014, "Adding limestone fines as cement paste replacement to reduce water permeability and sorptivity of concrete," Constr. Build. Mater., vol. 56, pp. 87-93, doi: 10.1016/j.conbuildmat.2014.01.066.

11. Knapen F. V. R. E., beeldens A., Van Gemert D., (2004) "E.Knapen, A. beeldens, D. Van Gemert, F.Van Rickstal, 'modification of cement concrete by means of polymers in solution'."

12. Abbas W. A., Korkess I. N., and Jasim M. H., 2018, "Investigation of the Optimal Percentage from Polyvinyl Alcohol on Flexural Strength of Cement Mortar Composite," Int. J. Eng. Technol., vol. 7, no. 4.20,p.584,doi: 10.14419/ijet.v7i4.20.26423.

13. Mohamed A. M., Osman M. H., Smaoui H., Azreen M., and Ariffin M., 2018, "Durability and Microstructure Properties of Concrete with Arabic Gum Biopolymer Admixture," doi: 10.1155/2018/1962832.

14. Courard L., Herfort D., and Villagran Y., 2016,"Performances of Limestone Modified Portland Cement and Concrete," Cement, vol. 1, no. 2001, pp. 1-31.

15. IQS.1993, "Iraqi specification for Portland cement test no. (5)."

16. IQS, “ASTM C 778 ' Standard Specification for Standard Sand'."

17. IQS ,"ASTM C150 'Standard specification for Portland cement.",

18. IQS, "ASTM C192 'Making and curing concrete test specimens in the laboratory'."

19. IQS, “ASTM C596 "Drying shrinkage of mortar containing hydraulic cement."

20. IQS, "ASTM C305, 2004, 'Standard method of test for mechanical mixing of hydraulic cement pastes and mortars of plastic consistency" 